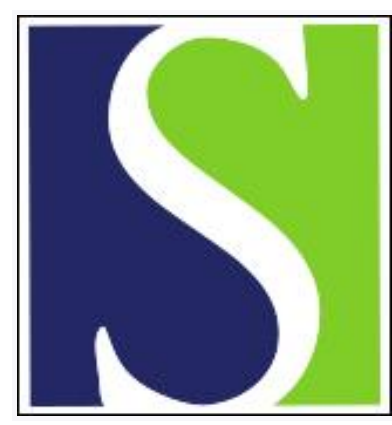

Scand J Work Environ Health 1988;14(3):197-200

https://doi.org/10.5271/sjweh.1931

Issue date: Jun 1988

Mortality and cancer incidence among marine engineers and machinists in Iceland.

by Rafnsson V, Johannesdottir SG, Oddsson H, Benediktsson H, Tulinius $\mathrm{H}$, Magnusson $\mathrm{G}$

Affiliation: Department of Occupational Medicine, Administration of Occupational Safety and Health, Reykjavik, Iceland.

This article in PubMed: www.ncbi.nlm.nih.gov/pubmed/3393856

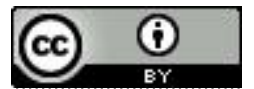




\title{
Mortality and cancer incidence among marine engineers and machinists in Iceland
}

\author{
by Vilhjálmur Rafnsson, MD, PhD, ${ }^{1}$ Soffía G Jóhannesdóttir, BSc, ${ }^{1}$ Hjörtur Oddsson, MD, ${ }^{1}$ \\ Hallgrimur Benediktsson, MD, ${ }^{2}$ Hrafn Tulinius, MD, ${ }^{3}$ Guðjón Magnússon, MD, $\mathrm{PhD}^{4}$
}

\begin{abstract}
RAFNSSON V, JÓHANNESDÓTTIR SG, ODDSSON H, BENEDIKTSSON H, TULINIUS H, MAGNÚSSON G. Mortality and cancer incidence among marine engineers and machinists in Iceland. Scand $J$ Work Environ Health 14 (1988) 197-200. A retrospective cohort study of mortality and cancer morbidity was carried out among 295 marine engineers and 182 machinists with special regard to cancer of the lung. The cohort was defined as all graduates from engineering and machinists school in Iceland during 1936-1955. During vocational training, as well as in their professional lives, marine engineers and machinists are exposed to asbestos, different kinds of mineral oils, and exhaust gases with marked individual variation as regards mode and magnitude of exposure. For deaths occurring between 1951 and 1982 information was obtained from the Statistical Bureau of Iceland. Significantly increased standardized mortality ratios were determined for cancer of the trachea, bronchus, and lung for the entire cohort. Record linkage with the Cancer Register revealed 36 cancers in the period 1955-1982. No statistically significant excess was found for the overall cancer incidence or for the incidence of cancer at any particular site. A special survey of smoking status showed that cigarette smoking was not as common among the subjects of the cohort as among the general male population in Reykjavik. These results support the suggestion that the increased mortality of lung cancer in the study group had a causal relationship to occupational exposure, particularly to asbestos exposure.
\end{abstract}

Key terms: asbestos, drowning accidents, lung cancer, retrospective cohort study, smoking habits.

Several studies have found a relation between asbestos exposure and pleural changes, particularly pleural plaques $(7,10,11)$, asbestos exposure and mortality from lung cancer, and asbestos exposure and malignant mesothelioma $(19,20,21,24)$. The relation between asbestos exposure and lung cancer is the most important.

Recent studies on marine engineers revealed an unexpectedly high prevalence of pleural plaques, and this high prevalence was thought to indicate previous asbestos exposure (3). Another study showed an excess risk of occupational cancer among machinists employed by railroad and other industries (18). These findings of occupational cancer have also been attributed to occupational exposure to asbestos.

The present study represents one phase of an ongoing study on the possible effect of asbestos exposure on Icelandic workers, and it was undertaken with the main objectives of determining whether mortality from lung cancer is excessive among Icelandic marine en-

1 Department of Occupational Medicine, Administration of Occupational Safety and Health, Reykjavik, Iceland.

2 Department of Pathology, University of Iceland.

3 The Icelandic Cancer Register, Icelandic Cancer Society, Reykjavik, Iceland.

4 Department of Social Medicine, University of Iceland, Reykjavík, Iceland.

Reprint requests to: Dr V Rafnsson, Department of Occupational Medicine, Administration of Occupational Safety and Health, Bildshofda 16, 112 Reykjavík, Iceland. gineers and machinists and of describing the mortality and cancer incidence patterns of these workers.

\section{Subjects and methods}

This is a retrospective cohort study with the cohort defined as all marine engineers and certified machinists recorded in the Register of Icelandic Engineers in 1911-1972 (2), born between 1905 and 1945, and graduated from the Engineers School of Iceland or completed courses given by the Fishing Association of Iceland in 1936-1955. The study population comprised 295 marine engineers and 182 machinists.

The Engineers School requires a four-year apprenticeship as a blacksmith for admission. Admission into the course of the Fishing Association requires two years of practical experience in a mechanical industry. During these training periods both groups presumably were exposed to a variable amount of asbestos. Exposure to asbestos continued in their later careers as engineers and machinists, and, in addition, they were exposed to various mineral oils, organic solvents, and exhaust gases with marked individual variations as regards mode and magnitude of exposure. Many of the subjects worked on board ships and fishing boats for some time after graduation, but most have eventually become employed as stationary engineers and/or boiler men on shore.

The subjects were traced through the National Registry and the Register of Deceased, Statistical Bureau of Iceland, as of 1 December 1982. Those not found 
Table 1. Lung cancer (malignant neoplasms of the trachea, bronchus and lung) mortality for all the subjects in 1951-1982 and for those with 20- and 30-year latency periods. $10=0 \mathrm{~b}$ served number of deaths, SMR = standardized mortality ratio)

\begin{tabular}{lccc}
\hline Group & Person-years & O & SMR \\
\hline $\begin{array}{l}\text { Marine engineers } \\
\text { and machinists combined }\end{array}$ & & & \\
$\quad$ All & 13437 & 7 & $205^{*}$ \\
$\quad$ Latency of 20 years & 6021 & 6 & $195^{\star}$ \\
$\quad$ Latency of 30 years & 1820 & 4 & $255^{*}$ \\
Marine engineers & 8239 & 3 & 175 \\
$\quad$ Alf & 3467 & 3 & 197 \\
$\quad$ Latency of 20 years & 911 & 2 & 290 \\
$\quad$ Latency of 30 years & & & \\
Machinists & 5198 & 4 & $234^{\star}$ \\
$\quad$ All & 2554 & 3 & 194 \\
Latency of 20 years & 909 & 2 & 225 \\
\hline Latency of 30 years & & & \\
\hline
\end{tabular}

${ }^{*} \mathrm{P}<0.05$, one-tailed.

in this manner had all emigrated. Information regarding their vital status was obtained from Icelandic embassies abroad, foreign population registries, and relatives remaining in Iceland. Vital status was ascertained for all of the subjects. Death certificates were obtained from the Statistical Bureau of Iceland and from abroad, and they provided causes of death according to official classification. As different revisions of the International Classification of Diseases were used during the study period, 1951-1982, the causes of death were reclassified to comply with the seventh revision.

The person-years of observation were counted from the time of graduation until death or until 1 December $1982(3,17)$. The expected numbers of deaths were calculated on the basis of person-years of observation within five-year age categories during respective single calendar years of the study period, multiplied by the cause- and calendar-year-specific death rates for Icelandic men $(3,17)$. Numbers of death by calendar years within five-year age groups were only available in manuscript form from the Statistical Bureau of Iceland and were entered into our computer for the purposes of this study. The records prior to 1951 were incomplete, and before that year some death certificates were attested to by clergymen rather than by doctors. Therefore it was only considered valid to study the following groups of causes of death for the period before 1951: deaths from all causes; deaths from accidents, poisoning and violence; and the subcategory of drowning in water transport accidents.

The ratio between observed and expected numbers, or the standardized mortality ratio (SMR), was calculated.

The personal identification number of each subject in the study population was linked with the Icelandic Cancer Register, which has records of cancer incidence since 1955 (4). The expected numbers of cancers were calculated in a manner similar to that described for the expected number of deaths, and similarly the standardized incidence ratio (SIR) was calculated.
In the evaluation of the statistical significance of the results concerning deaths from lung cancer and lung cancer incidence, the one-tailed $\mathrm{P}$-values were determined from a chi-square table $(3,6)$.

On the assumption of a Poisson distribution $(3,6)$, the $95 \%$ confidence intervals were calculated for the SMR and SIR values. When the confidence intervals did not contain 100 , the SMR or the SIR was statistically significant at the $5 \%$ level (two-tailed).

In a separate analysis of the material the SMR and SIR values were calculated with the use of 20 - and 30-year latency periods and for subcohorts of marine engineers and machinists.

\section{Results}

The observed numbers of deaths from lung cancer in the different groups of marine engineers and machinists are shown in table 1 . The observed numbers exceeded the expected, and the differences were statistically significant at the $5 \%$ level (one-tailed) for the groups of marine engineers and machinists together and for the subgroup of machinists, without the requirements of a latency period. The number of personyears is also shown for each group.

The observed incidence of lung cancer was 6 versus 4.94 expected (SIR 121), and this value was not significant at the $5 \%$ level (one-tailed).

The SMR values were calculated for 477 engineers and machinists in the total cohort for the whole study period (1936 to 1982) for all causes of death; accidents, poisonings and violence; and drowning in water transport accidents. The SMR for all causes of death was 94, which was not statistically significant. For accidents, poisonings and violence there were 22 deaths against 19.7 expected. An excess of deaths was observed for drowning in water transport accidents. It was statistically significant at the $5 \%$ level and yielded an SMR value of 225 ( 9 observed versus 4.0 expected).

Table 2 shows the SMR values for all causes of death and for specific causes of death during the period 1951-1982. The observed number of deaths for all causes was 85 against 93.9 expected. There were excess deaths from cancer of the bladder and cerebrovascular diseases, the SMR being 299 and 155, respectively. Table 2 also shows the SMR values for the subjects with latency periods of 20 years. There was an excess in lung cancer, cancer of the bladder, and cerebrovascular diseases (SMR values of 195, 357, and 175, respectively) for this group. When determined for a latency period of 30 years, the SMR values for the same causes of deaths were 255,741 , and 243 , respectively. The SMR for all causes of death increased with longer latency periods; it was the same as concerns the SMR for cancer of the bladder and cerebrovascular diseases.

Dividing the groups into marine engineers and machinists gave rise to similar results. Since the groups 
Table 2. Mortality, according to cause, for all the subjects in $1951-1982$ and for those with a 20 -year latency period. $(0=$ observed number of deaths, SMR = standardized mortality ratio, $95 \% \mathrm{Cl}=95 \%$ confidence interval)

\begin{tabular}{|c|c|c|c|c|c|c|}
\hline \multirow{2}{*}{ Cause of deatha } & \multicolumn{3}{|c|}{ All subjects } & \multicolumn{3}{|c|}{$\begin{array}{l}\text { Subjects with a } 20 \text {-year } \\
\text { latency period }\end{array}$} \\
\hline & $\mathrm{O}$ & SMR & $95 \% \mathrm{Cl}$ & $\mathrm{O}$ & SMR & $95 \% \mathrm{Cl}$ \\
\hline Malignant neoplasms (140-205) & 18 & 87 & $52-138$ & 14 & 84 & $46-141$ \\
\hline $\begin{array}{l}\text { Stomach (151) } \\
\text { Large intestine }(152,153)\end{array}$ & $\begin{array}{l}3 \\
1\end{array}$ & $\begin{array}{l}61 \\
77\end{array}$ & $\begin{array}{r}13-178 \\
2-429\end{array}$ & $\begin{array}{l}2 \\
0\end{array}$ & 53 & $6-192$ \\
\hline $\begin{array}{l}\text { Trachea, bronchus and lung } \\
(162,163)\end{array}$ & 7 & 205 & $83-423$ & 6 & 195 & $72-425$ \\
\hline $\begin{array}{l}\text { Kidney }(180) \\
\text { Bladder }(181) \\
\text { Other }\end{array}$ & $\begin{array}{l}1 \\
2 \\
4\end{array}$ & $\begin{array}{r}98 \\
299 \\
46\end{array}$ & $\begin{array}{r}2-546 \\
36-1078 \\
13-117\end{array}$ & $\begin{array}{l}1 \\
2 \\
3\end{array}$ & $\begin{array}{r}122 \\
357 \\
44\end{array}$ & $\begin{array}{r}3-679 \\
43-1296 \\
9-128\end{array}$ \\
\hline $\begin{array}{l}\text { Cerebrovascular diseases } \\
(330-334)\end{array}$ & 9 & 155 & $71-294$ & 8 & 175 & $76-345$ \\
\hline Ischemic heart disease (420) & 32 & 103 & $71-146$ & 31 & 114 & $77-161$ \\
\hline Respiratory disease $(470-527)$ & 4 & 104 & $28-267$ & 4 & 136 & $37-347$ \\
\hline $\begin{array}{l}\text { Accidents, poisonings and } \\
\text { violence (E800-E985) }\end{array}$ & 15 & 91 & $51-151$ & 7 & 92 & $37-190$ \\
\hline $\begin{array}{l}\text { Drowning in water transport } \\
\text { accidents (E851) }\end{array}$ & 4 & 178 & $48-455$ & 2 & 263 & $32-951$ \\
\hline All other causes & 7 & 43 & $17-089$ & 6 & 56 & $21-122$ \\
\hline All causes (001-E985) & 85 & 91 & $72-112$ & 70 & 100 & $78-127$ \\
\hline
\end{tabular}

a Code of the International Classification of Diseases, seventh revision, in parentheses.

were small and the cases few, the confidence intervals were wide, and no SMR was statistically significant.

Table 3 shows the SIR values for all cancers and for particular cancer sites among the subjects during the period 1955 to 1982 . The observed number of cancers was 36 against 34.71 expected. There were few cancers at each site, and the SIR values were generally low and in no case statistically significant. The results were similar when analyzed with 20 and 30 years' latency and when the cohort was divided into subcohorts of marine engineers and machinists.

\section{Discussion}

The present study represents the first attempt to describe the mortality pattern for a defined cohort of workers in Iceland. Our results indicate that marine engineers and machinists are at an excess risk of drowning in water transport accidents. The excess of drowning in water transport accidents was expected, as many subjects worked at sea early in their careers.

The main objective of our study was to investigate whether asbestos exposure could be detected through an excess mortality due to lung cancer. The results show a statistically significant excess death rate from lung cancer among the subjects.

The validity of a study such this one may be flawed from the misreading of information about the identification of the subjects (9). Such an occurrence would result in errors regarding vital status of the subjects or the cancer morbidity. In order to prevent such errors, we compared the information gathered from the Registry of Icelandic Engineers twice. This was a manual process, but, as it was performed twice, the information was considered to be correctly gathered
Table 3. Observed cancer incidence for primary sites for 461 subjects in 1955-1982. ( $O=$ observed incidence number $\mathrm{SIR}=$ standardized incidence ratio, $95 \% \mathrm{Cl}=$ confidence in terval)

\begin{tabular}{lrrr}
\hline Site $^{\text {a }}$ & O & SIR & \multicolumn{1}{c}{$95 \% \mathrm{Cl}$} \\
\hline Lip (140) & 2 & 282 & $34-1018$ \\
Stomach (151) & 4 & 63 & $17-160$ \\
Colon (153) & 1 & 43 & $1-240$ \\
Rectum (154) & 2 & 185 & $22-669$ \\
Larynx (161) & 1 & 154 & $4-857$ \\
Trachea, bronchus and & 6 & 121 & $45-264$ \\
lung (162) & 5 & 157 & $51-366$ \\
Prostate (177) & 2 & 101 & $12-363$ \\
Kidney (180) & 3 & 126 & $26-367$ \\
Bladder and other & 1 & 455 & $12-2533$ \\
urinary organs (181) & 9 & 83 & $38-158$ \\
Eye (192) & 36 & 104 & $72-144$ \\
Other sites & & & \\
\hline All sites (140-205) & &
\end{tabular}

a Code of the International Classification of Diseases, seventh revision, in parentheses.

from the sources. Other parts of the analysis, including the tracing of the subjects through the Cancer Registry and the statistical evaluations, were done by computer, a procedure ascertaining similar treatment of the information from both the study group and the general population.

We have assumed that the smoking habits of the cohort parallel those of the general population. However, should this not be the case, smoking might constitute a serious confounding factor $(1,3,9,17)$. We therefore made an effort to estimate the smoking status of the cohort, as well as that of the general male population. The Heart Association in Iceland conducted a 
Table 4. Smoking status, according to the results of a survey made by the Heart Association in 1967-1981, of 184 marine engineers and machinists of the present study and of all the participants in the survey of the Heart Association.

\begin{tabular}{|c|c|c|c|c|}
\hline \multirow{3}{*}{ Smoking status } & \multicolumn{4}{|c|}{ Survey of the Heart Association } \\
\hline & \multicolumn{2}{|c|}{$\begin{array}{c}\text { Marine engineers and } \\
\text { machinists belonging } \\
\text { to the present study } \\
(N=184)\end{array}$} & \multicolumn{2}{|c|}{ All participants } \\
\hline & $\mathbf{N}$ & $\%$ & N & $\%$ \\
\hline Never a smoker & 38 & 20.7 & 1940 & 21.9 \\
\hline Ex-smoker & 40 & 21.7 & 1975 & 22.3 \\
\hline Pipe or cigar smoker & 59 & 32.1 & 2295 & 25.9 \\
\hline Cigarette smoker & 47 & 25.5 & 2656 & 30.0 \\
\hline $\begin{array}{r}1-4 \text { cigarettes } / d \\
5-14 \text { cigarettes } / d \\
15-24 \text { cigarettes } / d \\
\geq 25 \text { cigarettes } / d\end{array}$ & $\begin{array}{r}10 \\
15 \\
14 \\
8\end{array}$ & $\begin{array}{l}5.4 \\
8.2 \\
7.6 \\
4.3\end{array}$ & $\begin{array}{r}319 \\
680 \\
1166 \\
491\end{array}$ & $\begin{array}{r}3.6 \\
7.7 \\
13.2 \\
5.5\end{array}$ \\
\hline
\end{tabular}

comprehensive population study from 1967 to 1981 on samples of men living in the Reykjavík area. A computer search of the files of the Heart Association revealed that 184 individuals of our cohort of 477 had, indeed, participated in the population study and had filled out a questionnaire about their smoking habits. Table 4 shows the smoking status of all participants in the survey, as well as that of the 184 engineers and machinists, as the information was recorded on their Heart Association questionnaire. Twenty-six percent of this group was currently smoking cigarettes as opposed to $30 \%$ of all male participants. The excess risk of dying from lung cancer detected among the study group can, therefore, hardly be ascribed to more cigarette smoking than in the general population. The mean ages of the subjects in the study group and the participants in the Heart Association survey were similar.

The healthy worker effect, which is usually detectable in studies of this kind $(8,23)$, was weak and was not to be seen with 20 and 30 years of latency.

In addition to an excess mortality due to lung cancer the results indicate an excess mortality from cancer of the bladder and from cerebrovascular diseases. Cancer of the bladder has been related to industrial exposure to certain aromatic amines (5). A case-referent study (16) has also shown a relation between cancer of the bladder and occupation in leather and rubber industries, as well as in iron- and metalwork.

It is difficult to identify a biological explanation for the relation between excess mortality from cerebrovascular diseases and the workplaces of engineers and machinists. One might, however, speculate that the high and sustained noise levels may lead to elevated blood pressure (2), which in turn may lead to cerebrovascular diseases $(14,15,22)$.

\section{References}

1. Ahlbom A, Norell S. Grunderna i epidemiologi. Studentlitteratur, Lund 1981.

2. Andrén L. Cardiovascular effects of noise. Acta Med
Scand Suppl 657211 (1982) 1-41.

3. Axelson $\mathrm{O}$. Epidemiologi för arbets- och miljömedicin. Studentlitteratur, Lund 1981.

4. Bjarnason Ó, Tulinius H. Cancer registration in Iceland 1955-1974. Act a Pathol Microbiol Immunolog Scand Suppl 281 (1983) 1-120.

5. Clayson DB. Occupational bladder cancer. Prev Med 5 (1976) 228-244.

6. Documenta Geigy. Scientific tables. Seventh edition. Ciba-Geigy, Basel 1971.

7. Freudlich IM, Greening RR. Asbestosis and associated medical problems. Radiology 89 (1967) 224-229.

8. Hernberg S. Epidemiology in occupational health. In: Zenz C, ed. Development in occupational medicine. Year Book Medical Publisher, Chicago, IL 1980, pp 1-40.

9. Hernberg S. Evaluation of epidemiologic studies in assessing the long-term effects of occupational noxious agents. Scand J Work Environ Health 6 (1980) 163-169.

10. Hillerdal G. Pleural plaques in a health survey material: Frequency, development and exposure to asbestos. Scand J Respir Dis 59 (1978) 257-263.

11. Hourihane DO'B, Lessof L, Richardson PC. Hyaline and calcified pleural plaques as an index of exposure to asbestos - A study of radiological and pathological features of 100 cases with a consideration of epidemiology. Br Med J 1 (1966) 1069-1074.

12. Ingimarsson Ó. Vélstjóratal 1911 -1972. Vélstjórafélag Îsland, Reykjavík 1974.

13. Jones RN, Diem JE, Ziskand MM, Rodriguez M, Weill H. Radiographic evidence of asbestos effect in American marine engineers. J Occup Med 26 (1984) 281-284.

14. Kannel WB. Some lessons in cardiovascular epidemiology from Framingham. Am J Cardiol 37 (1976) 269282.

15. Kannel WB, Gordon T, Wolf PA, McNamara P. Hemoglobin and the risk of cerebral infarction: The Framingham study. Stroke 3 (1972) 409-420.

16. Lockwood K. On the etiology of bladder tumors in København-Frederiksberg: An inquiry of 369 patients and 369 controls. Acta Pathol Microbiol Scand Suppl 14551 (1961) 1-166.

17. MacMahon B, Pugh TF. Epidemiology. Principles and methods. Little, Brown and Company, Boston, MA 1970.

18. Mancuso TF. Mesothelioma among machinists in railroad and other industries. Am J Ind Med 4 (1983) 501513.

19. Ohlson C-G, Klaesson B, Hogstedt C. Mortality among asbestos-exposed workers in a railroad workshop. Scand J Work Environ Health 10 (1984) 283-291.

20. Peto J, Doll R, Howard SV, Kinlen LJ, Lewinsohn HC. A mortality study among workers in an English asbestos factory. Br J Ind Med 34 (1977) 169-173.

21. Selikoff $1 J$, Hamond C, Seidman H. Mortality experience of insulation workers in the United States and Canada, 1943-1976. Ann NY Acad Sci 330 (1977) 91116.

22. Tibblin G, Wilhelmsen L, Verkö L. Risk factors for myocardial infarction and death due to ischemic heart disease and other causes. Am J Cardiol 35 (1975) 514522.

23. Wen CP, Tsai SP, Gibson RL. Anatomy of the healthy worker effect: A critical review. J Occup Med 25 (1983) $283-289$.

24. Wignall BK, Fox AJ. Mortality of female gas mask assemblers. Br J Ind Med 39 (1982) 24-28.

Received for publication: 29 January 1988 